\title{
Can Indifference Make the World Greener?
}

\author{
Johan Egebark and Mathias Ekström
}




\title{
Can Indifference Make the World Greener?
}

\author{
Johan Egebark \& Mathias Ekström*
}

September 10, 2013

\begin{abstract}
We test whether people's tendency to stick with the default option can help save resources. In a natural field experiment we switch printers' default settings, from simplex to duplex printing, at a large Swedish university. The results confirm that roughly one third of all printing is determined by the default alternative, and hence daily paper consumption drops by 15 percent due to the change. The effect is immediate, lasts throughout the experimental period, and remains intact after six months. We also investigate how the more conventional method of encouraging people to save resources performs, and find it has no impact. Recent theoretical and empirical contributions indicate that the default effect works through recommendation, depends positively on the number of alternatives in the choice set, and is reinforced for difficult decisions. We demonstrate that the default option matter in a simple, non-dynamic, decision task with only two alternatives, and where people have been explicitly informed about the recommended course of action.
\end{abstract}

Key words: Default option; Resource Conservation; Natural Field Experiment

JEL classification: C93; D03; Q50

\footnotetext{
*Egebark: Department of Economics, Stockholm University and the Research Institute of Industrial Economics (IFN). Email: johan.egebark@ne.su.se. Ekström: Department of Economics, Stockholm University and the Research Institute of Industrial Economics (IFN). Email: mathias.ekstrom@ne.su.se.

We wish to thank Rachel Croson, Tom Cunningham, Stefano DellaVigna, Peter Fredriksson, Magnus Johannesson, Therese Lindahl, Peter Martinsson, Peter Skogman Thoursie and Robert Östling for valuable comments. Seminar participants at NHH in Bergen, and the EAERE Conference in Toulouse 2013 also provided helpful comments. We also want to express our gratitude to Jenny Lilliehöök, Fredrik Holm and Miroslav Lustinsky for administrative support, as well as all participating departments. Financial support from the Jan Wallander and Tom Hedelius Foundation is gratefully acknowledged. All errors are our own.
} 


\section{Introduction}

There is a growing interest in the potential role of non-price based behavioral interventions to address key policy issues (Thaler and Sunstein, 2008; Allcott and Mullainathan, 2010; Shafir, 2012). Following rapid population growth and increasing environmental threats, one area where such interventions have an important role to play is resource conservation (Allcott and Mullainathan, 2010). Recent work has shown that simple social comparison can be used to decrease energy consumption (Nolan et al., 2008; Ayres et al., 2009; Allcott, 2011; Costa and Kahn, 2013) and water waste (Goldstein et al., 2008), and promote environmentally friendly agricultural practices (Chen et al., 2009). As suggested by DellaVigna (2009), one of the most powerful behavioral tools is the default option, i.e., the alternative you obtain when not actively making a choice. Defaults determine, for example, how much people save for retirement (Madrian and Shea, 2001) or whether they become an organ donor (Johnson and Goldstein, 2003; Abadie and Gay, 2006). Given that defaults strongly influence choices, there is surprisingly little evidence on whether and how green defaults affect behavior. In this paper we aim to fill in parts of this gap by testing whether a simple change in the default can improve efficiency in a setting that in a global perspective consumes a vast amount of resources every single year: document printing. When sending documents to a printer, the user can typically choose whether to print on both sides of a sheet of paper (duplex) or to print on only one side (simplex). Duplex printing reduces the number of sheets in the production of a document and is thus less resource intensive (i.e. greener). A common feature in this setting is the existence of a pre-set default alternative, from which users can easily opt out with a simple mouse click. In a natural field experiment we switch the default from simplex to duplex on printers at a large Swedish university. We also investigate how well the more conventional method of encouraging people to take responsibility performs. Prior to the default switch, an e-mail from the environmental coordinator at the university encouraged employees in a subgroup of departments to print duplex as much as possible.

The present study relates to the broader scientific interest in understanding default effects (Anderson, 2003; Dinner et al., 2011). Conducting an experiment in the field is warranted given 
that previous evidence on the impact of defaults is almost exclusively based on either laboratory experiments, often with hypothetical questions, (Samuelson and Zeckhauser, 1988; Johnson et al., 1993; Park et al., 2000; Brown and Krishna, 2004; McKenzie et al., 2006; Fleming et al., 2010; Dinner et al., 2011), or observational data (Madrian and Shea, 2001; Johnson and Goldstein, 2003; Abadie and Gay, 2006; Pichert and Katsikopoulos, 2008; Haggag and Paci, forthcoming). ${ }^{1}$ To the best of our knowledge, Löfgren et al. (2012) is the only other natural field experiment as defined by Harrison and List (2004) that explores the default effect. They find the default alternative to be irrelevant for the decision whether to offset travel-related $\mathrm{CO}_{2}$-emissions or not. However, since they study a group of well-informed individuals (participants in an environmental conference) we cannot tell whether the null-result is a consequence of the setting or the fact that they use a different method (Al-Ubaydli and List, 2012). Hence, experimental evidence from natural settings populated with more representative samples is needed. Second, recent theoretical and empirical contributions suggest that default effects depend positively on the number of alternatives in the choice set (Dean, 2008), are reinforced for difficult decisions (Fleming et al., 2010), and partially work as implicit recommendations (McKenzie et al., 2006). We test whether defaults matter in a simple, non-dynamic, decision task with only two alternatives, where people have been explicitly informed about the recommended course of action and where opting out of the default is as easy as a mouse click.

The experiment offers a number of insights that can inform public policy. First, we find a substantial and immediate default effect. On average, daily paper consumption drops by 15 percent due to the change, and this reduction occurs the very day of the intervention. Put differently, the default determines how one third of all documents will be printed. Interestingly, the magnitude of the effect does not diminish over time; more than six months after the intervention, consumption is still at the new lower level. Second, we show that the printing volume, measured as the number of printed pages and documents, is independent of the default option, meaning that the drop in paper usage is only due to an increase in the fraction of duplex sheets. This is important since it

\footnotetext{
${ }^{1}$ Arguably, Madrian and Shea (2001) and Haggag and Paci (forthcoming) have the most convincing identification strategy, whereas the cross-country analysis of organ donor behavior seems to some extent to be driven by unobserved factors (Coppen et al., 2005).
} 
suggests that using defaults as a policy tool avoids unintended adverse effects. (One example of a possible negative side effect would be that people start to print more documents because each document carried less weight.) As a comparison, Catlin and Wang (2013) find that people increase their paper usage when the possibility to recycle is introduced, and both Schultz et al. (2007) and Ayres et al. (2009) report that information about neighbors' energy usage causes some individuals to increase their consumption. (Fellner et al., 2013 find the same type of boomerang effect when studying tax compliance.) Third, we highlight why it is important to contrast earlier results that rely on observational data with results from experiments. In particular, if we were restricted to observational data only, we would, due to selection bias, overestimate the default effect by 50 percent. Finally, we show that encouraging people to use duplex printing as much as possible has no effect. This clearly indicates that trying to convince people to take responsibility, by simply asking, is inefficient. (The evidence in Anderson and Claxton, 1982 and Kallbekken et al., 2013 suggests that it is even debatable to what extent providing even richer information, coupled with educational activities, is effective, especially in the long run.)

The simple conceptual framework that we set up highlights the link between weak preferences and a low switching cost. Our interpretation, that the size of the default effect depends solely on the number of indifferent individuals in the population, resonates well with the null-finding in Löfgren et al. (2012), since they target a more selected population who likely have stronger preferences over alternatives. However, there are two competing explanations that we cannot rule out. First, based on the reasoning behind endowment effects (Kahneman et al., 1991), people's printing preferences might be shaped by the current default option, meaning that users emphasize positive characteristics of simplex printing when simplex is the default and vice versa when duplex is the default. Another possibility is that the default solves a coordination problem. People might, for example, prefer to print duplex if everyone else does so as well, and changing to duplex as default is a credible signal to users that this is likely to happen. Although we cannot rule out these possibilities, our interpretation is supported by Kahneman (2011), who stresses that default effects are best explained by the laziness of the rational System 2 (as opposed to most other framing effects that pertain to the insufficient System 1). Similarly, Sunstein and Reisch (2013) argue that 
defaults typically fail to stick when people have well defined preferences. Nevertheless, the setting we exploit illustrates that there exist scenarios where carefully choosing "no-action" options have a huge potential also when users are experienced and the default option is unlikely to be viewed as implicit recommendation.

Finally, calculating the monetary savings for the typical department (15-20 employees) in our experiment illustrates why we cannot expect management to bother about default settings. The net saving for a department in the experiment is roughly 60 USD per year, implying that a general shift to a green default is unlikely to occur on its own. This assertion is further supported by the fact that all but one department when asked were willing to change to duplex as default. Convincing manufactures to set green defaults as machines leave the factory may therefore be a fruitful strategy to reap benefits on a global scale. From a practical standpoint it is important to stress that people are most active when simplex is the default. This suggests that those in charge of selecting parameters can follow the guidelines in Johnson et al. (2012) and use duplex as default simply because it is the alternative that most people prefer. To put the potential impact in a broader perspective, back of the envelope calculations suggest that a switch to a green default in American offices alone could reduce the annual use of paper by 270,000 metric tons. This amounts to 780,000 metric tons of $\mathrm{CO}_{2}$-equivalents or, as a comparison, pulling 150,000 cars off the road. ${ }^{2}$

\section{The Experiment}

\subsection{Conceptual Framework}

In theory, it is possible to nudge people to take the environment into consideration if they disproportionally stick to the default option (Samuelson and Zeckhauser, 1988; Masatlioglu and Ok, 2005). For several reasons, document printing constitutes a clean testing ground for this hypothesis. First, the decision-maker faces two alternatives (simplex or duplex printing) where one (duplex printing)

\footnotetext{
${ }^{2}$ It is estimated that the average U.S. office worker uses 10,000 sheets of paper each year, implying that total paper usage amounts to 3.6 million metric tons annually (Cullen, 2007). Using this figure and assuming that, as in the experiment, 50 percent of all printing originates from printers with simplex as the default, we calculated the environmental impact estimates using the Environmental Paper Network Paper Calculator (www.papercalculator.org).
} 
is less resource intensive than the other, and where one is always the default option. Second, the cost of being active is close to zero: it constitutes the time spent navigating a pop-up window and executing one mouse click, which likely takes just a few seconds irrespective of experience. (The print screens of the pop-up window included in the appendix show how easy it is to opt out.) Third, in contrast to many other default scenarios, our setting is non-dynamic. In particular, the decision whether to be active or not when printing a specific document only affects the look of that document, not documents to be printed in the future. The non-dynamic setting facilitates the conceptual framework and precludes a default effect based on present-biased decision-makers (see, e.g., Choi et al., 2003; Carroll et al., 2009). ${ }^{3}$

The decision-maker will therefore be active if the immediate gain in utility is higher than the immediate cost. ${ }^{4}$ As the cost of being active is approaching zero, all individuals that have any preference in favor of the non-default option will switch. In practice, this means that only individuals with weak preferences, and those who prefer the current default, will abstain from switching. These conditions lead us to the following assertion: switching the default option will have an impact only if there are sufficiently many indifferent individuals in the population. ${ }^{5}$ We hypothesize that there is in fact a large enough mass of such individuals, and thus we predict that changing default in this setting will affect the relationship between simplex and duplex printing. Keeping track of how active people are in the two default regimes will inform us of people's printing preferences, and how intrusive the default switch actually appears to be.

\footnotetext{
${ }^{3}$ There is of course a possible long term benefit - a better environment - if a sufficient mass use duplex printing, but there is no intertemporal trade-off for the individual decision-maker. Note also that we switch the printers' default settings. People can also decide on their own computer's default settings and in that situation present-biased preferences could play a role. Whether this is the case or not is irrelevant in our analysis.

${ }^{4}$ With only two alternatives, we can formalize the decision whether to stick with the default or not in one simple expression:

$$
\max \left\{U(\text { active })-c_{\text {active }}, U(\text { default })\right\}
$$

Clearly, the decision-maker is active if the gain in utility is higher than the cost:

$$
U(\text { active })-U(\text { default })>c_{\text {active }}
$$

${ }^{5}$ Indifferent here refers both to those who are truly indifferent and to those whose preferences are weak enough for the tiny cost to factor in.
} 


\subsection{Design}

Over a period of three months we switched the default option (from simplex to duplex) on printers at a large Swedish university, with random timing of the intervention. To be able to carry out the experiment, we needed a large enough sample of printers that still had simplex as default, and that allowed for a switch in this default. ${ }^{6}$ In addition, we wanted to have easy access to the relevant print statistics; that is, each printer in the experiment had to digitally report, at minimum the number of printed sheets per day. The following steps generated the sample of printers that we used in the experiment. We asked the IT-support department at the university for a list of all printers that they had administer rights to, i.e., the printers that report sufficient statistics online. This original sample consists of 54 printers from 31 different departments. 19 of the departments had at least one printer that allowed for a change in the settings. We directly contacted the heads of these 19 departments, asking whether they would be willing to participate in the study. They were told about the intention of the study and that participation required that the default switch be communicated to staff from within the department, and not by us. (The e-mail employees received about the change in the settings is in the appendix.) We stressed that it was crucial that none of the staff, who are the subjects, was informed about the study. The fact that subjects were unaware of the experiment means that our study qualifies as a natural field experiment, as defined by Harrison and List (2004). 18 out of 19 departments accepted these terms and became part of the study. The high compliance rate suggests the departments had not originally chosen their default in a rational and informed way; rather, it seems as if they stuck to the default that was set when the printer was first installed and put to work. The 18 departments had in total 25 printers which we use in the experiment. ${ }^{7}$

Figure 1 illustrates the experimental design. The experiment consisted of three periods spread evenly over three months (15 weeks). We started with a pre-treatment phase of five weeks when all printers had simplex as default, and we ended with a post-treatment phase of five weeks when

\footnotetext{
${ }^{6}$ You may also ask how a switch from duplex to simplex impacts behavior. Our conjecture, however, was that very few departments would be willing to allow such an intervention.

${ }^{7}$ Naturally, the number of employees varies between departments; a rough calculation is that the average number is around 20 per printer.
} 
all printers had duplex as default. Between these, there was a treatment phase of five weeks, in which the 18 departments were randomly assigned to one of six different pre-determined switching dates. $^{8}$ As seen, the default switch occurred either in the first or the last week of the treatment phase. Importantly, we can follow the usage of each printer for at least a five-week before period (with simplex as default) and a five-week after period (with duplex as default). A random subset of departments (these were randomly assigned to a late switching date) were, prior to their default switch, exposed to what we denote as the encourage treatment. All employees in these departments were asked (via e-mail) to print duplex as much as possible, and were reminded of how simple it is to do this. The e-mail was signed by the environmental coordinator at the university and sent in the first week of the treatment phase, allowing for a four-week evaluation period. (The English version of the e-mail is in the appendix.) We deliberately had a person with some authority send the e-mail as we wanted to approximate, as much as possible, typical real world situations where individuals, or organizations, representing the green alternative try to encourage people to become more environmentally friendly. We anticipated that this approach would help shed some light on how much of the default effect is explained by pure suggestion. While such a mechanism is sometimes mentioned as a potential explanation in previous studies on default effects, almost nothing is known empirically about its relative importance. The inclusion of the encourage treatment (for a subset of departments) implies that we overweigh the probability to be assigned a late switching date. The departments that were assigned to the encourage treatment received the e-mail exactly four weeks prior to the default switch. During the four weeks, there were both printers that switched to duplex as default and printers that continued to have simplex as default.

\footnotetext{
${ }^{8}$ For departments that participate with more than one printer it would be strange to repeat the procedure, especially if there is little space in time between interventions. For that reason we used the department, and not the printer, as the unit of randomization.
} 
Figure 1: Experimental design

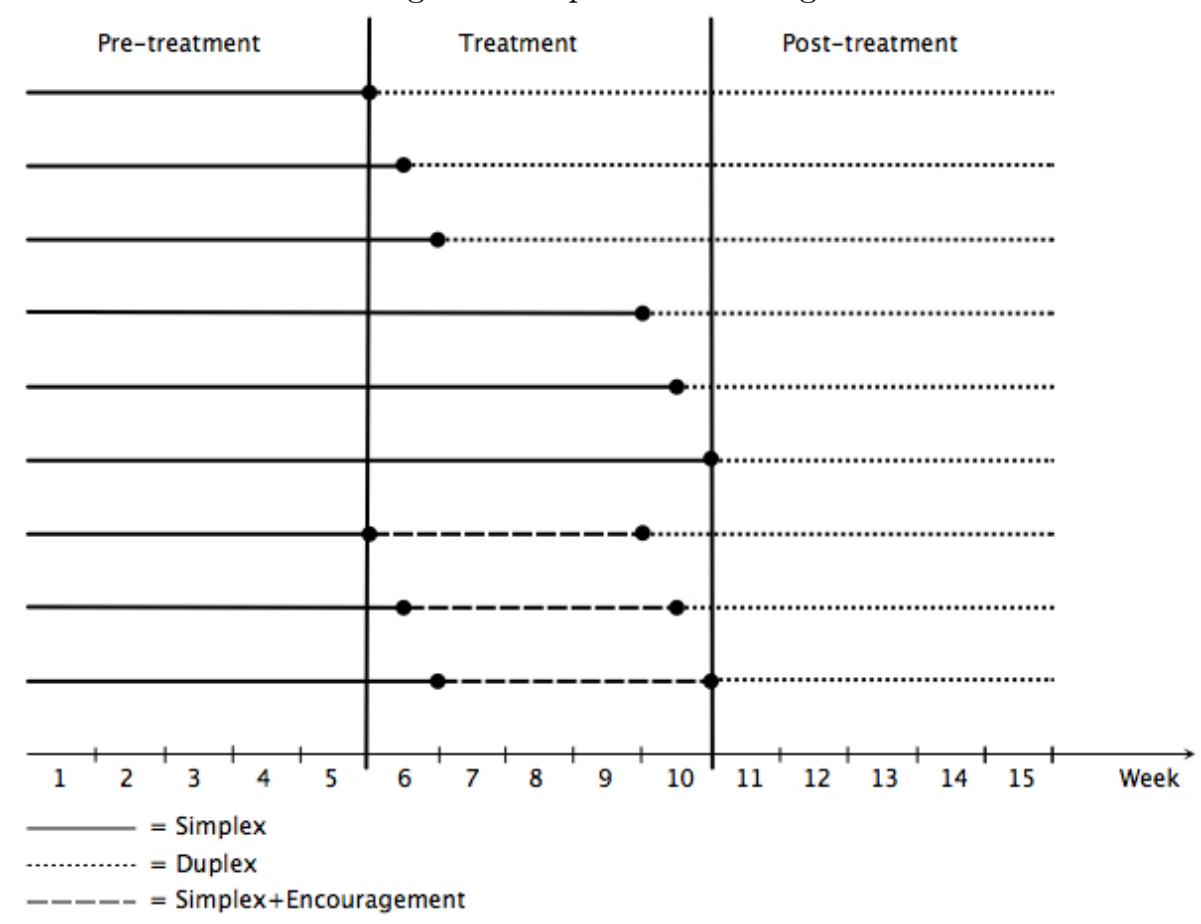

\section{Empirical Strategy and Data}

The staggered passage of changed print settings means that our experiment constitutes a controlled event study: all printers are used for the default treatment, but the timing of the intervention is random. The control group is therefore not restricted to printers whose settings are never changed. Rather, we can use as the control group all printers not receiving treatment at time $t$, even if they have already switched their default or will do so later on. Given the design, we measure the default effect by using all 25 printers, normalize time to zero, and compare mean outcomes before and after the intervention. Identification is more credible if there is a clear and visible shift in the outcome that appears close in time to the intervention. Since treatment occurs at different points in time, depending on the printer, it is unlikely that we confound a potential treatment effect with other time events. The encourage treatment can by studied in the same fashion, except that we here use 
a smaller sample of printers.

The outcomes of primary interest are: (1) the ratio of sheets over pages, (2) the number of duplex and simplex sheets, respectively and (3) the number of sheets. An interesting aspect, however, is whether there are spillover effects due to the new default settings. If a switch to duplex makes users more aware of environmental issues in general, they might respond by printing fewer documents. This would amplify the underlying default effect leading to an even larger reduction in the number of sheets. There is also the potential for the opposite effect: if users think that fewer sheets will be printed after the switch, they could (intentionally or unintentionally) respond by printing more documents, off-setting the underlying default effect. ${ }^{9}$ Despite all these possibilities, our conjecture is that the volume of printing, measured as the number of printed pages, will be unaffected.

Data were collected for each printer on a daily basis, implying that the unit of observation is printer and day. Table 1 presents summary statistics for the common (five week long) pretreatment period, when there are no interventions. Column 1 gives the figures for the 25 printers in the experiment. Mean values for the number of sheets in the second row are slightly lower than those for the number of pages, indicating that some of the documents, but not all, are printed using duplex. Rows 3-4 confirm that a little less than a third of the sheets are duplex sheets, despite the fact that the default setting is simplex. We also construct a measure for the degree of duplex printing. This measure is simply the ratio of the number of sheets to the number of pages, and hence takes values between 0.5 and 1 . If all printing is duplex the ratio is 0.5 , and the more simplex sheets there are, the higher the ratio. The printers in the experiment have a mean ratio of 0.86 , indicating that most printing is done using simplex. We note that the standard deviations (given in parentheses) are relatively large, suggesting there is considerable variation in printing across printers and over time. Finally, column 2 reports the usage for the subset of printers that, before the default switch, were exposed to the encourage treatment. It appears they barely differ from the bigger sample. For example, the sheets per page ratios are almost identical.

\footnotetext{
${ }^{9}$ The total number of printed pages may also increase (at least in the short run) if people have missed out on the information about the new print settings. You could imagine someone printing the same document twice because they used duplex unintentionally.
} 
Table 1: Summary statistics (before-period)

\begin{tabular}{lcc}
\hline & $(1)$ & $(2)$ \\
& All & Encouragement \\
\hline \hline No. pages & 235.6 & 263.7 \\
& $(517.9)$ & $(437.4)$ \\
No. sheets & 175.9 & 200.1 \\
& $(320.6)$ & $(309.4)$ \\
No. of duplex sheets & 60.32 & 63.6 \\
& $(213.3)$ & $(141.8)$ \\
No. of simplex sheets & 115.6 & 136.6 \\
& $(167.8)$ & $(200.6)$ \\
SP ratio & 0.856 & 0.850 \\
& $(0.153)$ & $(0.148)$ \\
\hline$N$ & 575 & 260 \\
No. of printers & 25 & 11 \\
No. of departments & 18 & 6 \\
\hline Notes: The table reports averages for the five & &
\end{tabular}

Notes: The table reports averages for the five week period without any interventions.

\section{Results}

\subsection{Main Findings}

To understand whether our interventions affect resource efficiency, we begin by having a closer look at the ratio of sheets to pages. This outcome takes values between 0.5 and 1 , with lower ratios indicating more duplex printing. Figure 2 shows daily means, before and after the respective treatments. ${ }^{10}$ In the leftmost scatter plot we notice the immediate default effect. The very day of the switch, the ratio drops from around 0.85 to 0.73 , and once the new level is reached it holds constant. As expected, the difference in means is highly significant: $t(1171)=13.65, p=0.000 .{ }^{11}$ The large difference suggests that the default option determines how one third of all documents is printed. In sharp contrast, there is no evidence of any effect for the encourage treatment in the right plot, not even the day the e-mail was sent $(t(388)=1.45, p=0.147)$. As seen in Figure 3, we

\footnotetext{
${ }^{10}$ To ensure a balanced panel, we restrict the time window to five (four) weeks before and after the default intervention (encouragement letter).

${ }^{11}$ The t-statistics in this section come from regressions of the respective outcome on a dummy variable that equals one for the first 25 days after a printer's default switch and zero for the 25 days prior to the switch. Given that we have at most 25 clusters we performed the regressions using both robust and cluster robust standard errors (by printer) and report p-values for the more conservative of the two.
} 
can confirm that the average default effect observed in Figure 2 is not driven by just a few units, as all 25 printers in the sample report an improvement in resource efficiency. As highlighted in the right graph, the effect is typically larger for printers reporting a low fraction of duplex printing before the change.

Figure 2: Sheets per page
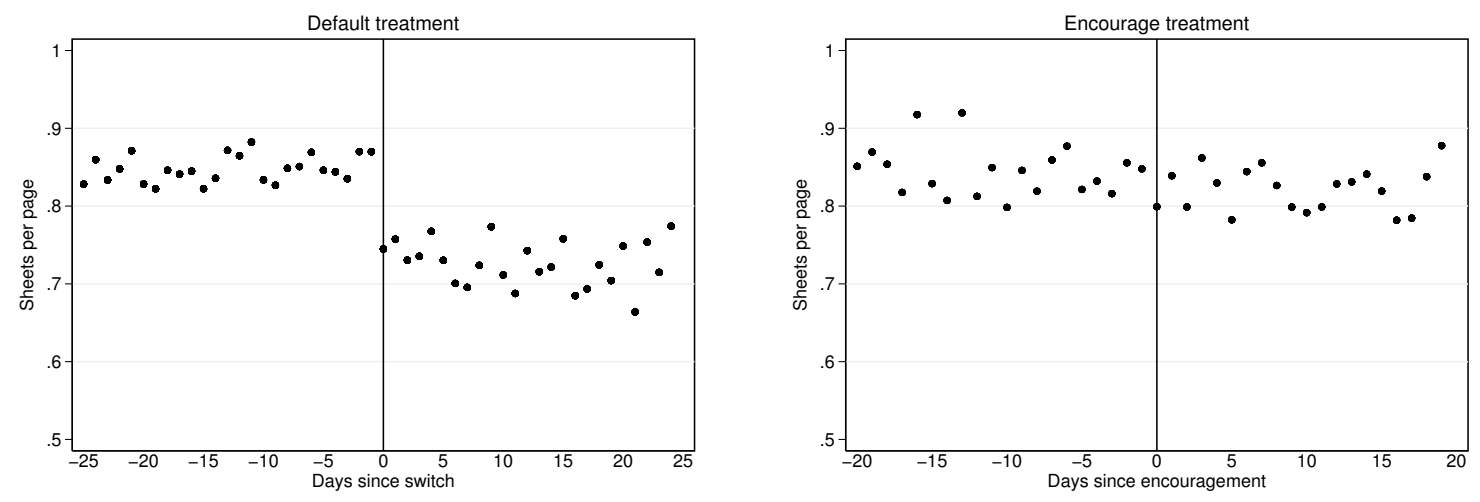

Figure 3: Sheets per page by printer: (left) Before/After, (right) Net effects
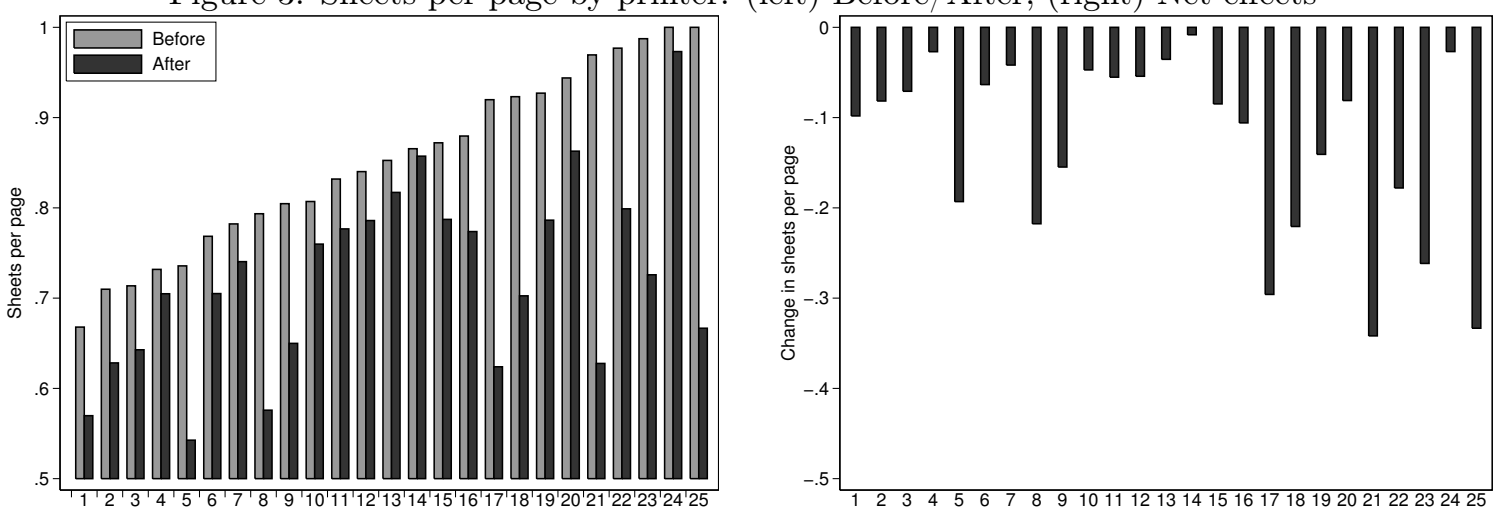

Increased efficiency does not automatically imply that resources are saved, since people may adapt their behavior and start using more of the resource. For example, car owners might begin to drive more frequently, or travel longer distances, as their cars become more fuel efficient. The left bar graph in Figure 4 indicates that the number of printed pages is unaffected by the new settings, suggesting that the users did not respond by starting to print more (or less) documents. In terms 
of a formal test, the difference in means before and after the intervention is far from significant $(t(1249)=0.53, p=0.593)$. In other words, and as expected, the printing volume is independent of the default setting. Instead, it is the relation between simplex and duplex printing that has shifted (gray and white bars). Prior to the switch, simplex printing is more than twice as common as duplex printing, whereas after the switch duplex and simplex printing are equally common. Both the reduction in the number of simplex sheets $(t(1249)=6.90, p=0.000)$ and the increase in the number of duplex sheets $(t(1249)=3.04, p=0.002)$ are highly significant. We also note that there is still a substantial amount of simplex printing after the duplex default has been implemented, suggesting it is (in practice, and not only in theory) easy for people to opt out if they wish. The net effect on the number of sheets is relatively large. On average, paper consumption has dropped with 15 percent (30 sheets) per day due to the default switch $(t(1249)=2.45, p=0.014)$. Turning to the encourage treatment in the bar graph to the right, there is no evidence that asking people to use duplex has any impact. In particular, comparing bars on either side of the vertical line, there is no drastic shift in the relation between duplex and simplex printing. (This conclusion is confirmed by t-tests.) The total decrease in paper usage due to the new default settings is illustrated in Figure 5: in the first 25 days after the switch, the 18 departments saved 15,000 sheets of paper. Notably, the total number of printed pages is (almost) exactly the same in both periods.

Figure 4: Printed pages and sheets (total, simplex, duplex)
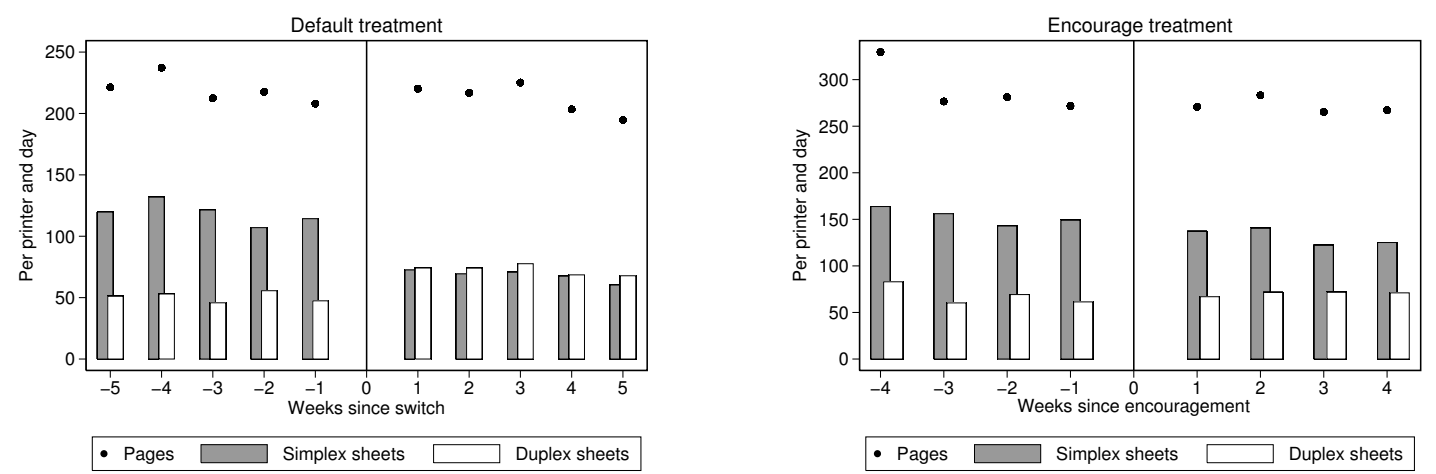


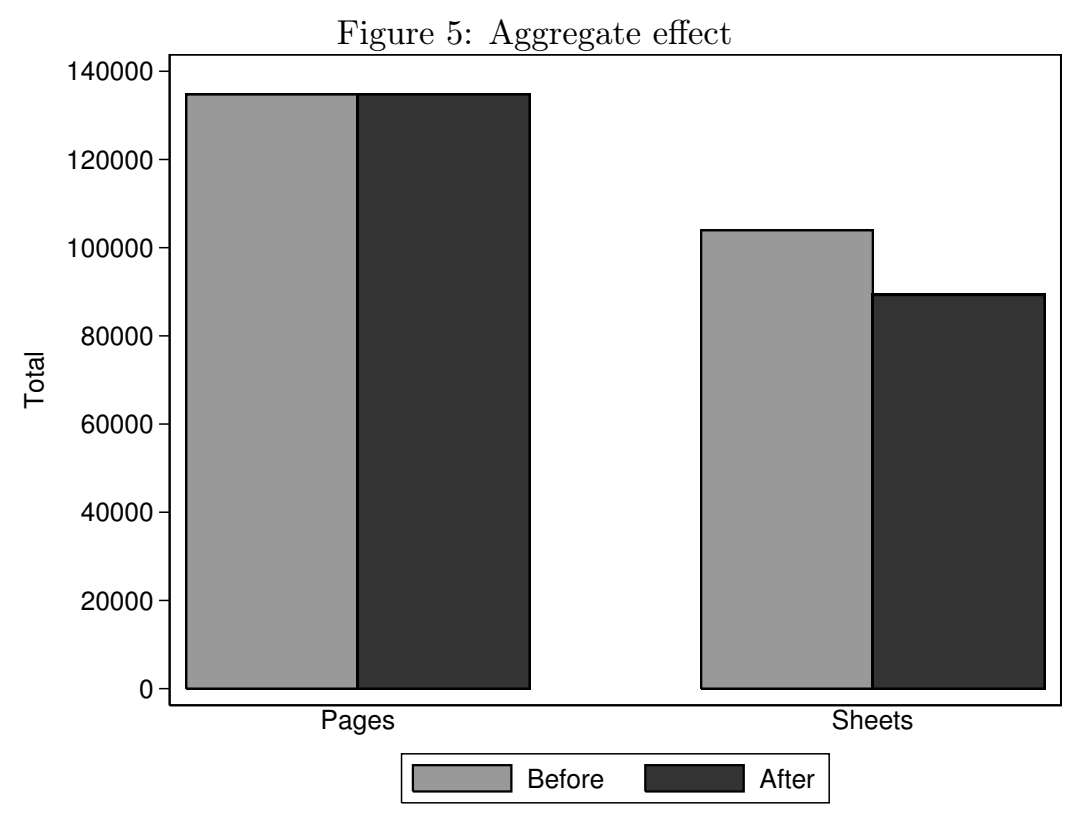

While many behavioral interventions, such as social comparison and feedback, often have (large) short-run effects, there is limited evidence on the long-run impacts (Allcott and Rogers, 2012). An interesting question, therefore, is whether default effects endure in the longer run. To investigate this we collected additional data during a second consecutive five week period, commencing 28 weeks after the intervention. Figure 6 plots weekly averages for the outcome sheets per page. If people reverted back to simplex printing in the long run, we would expect this outcome to be close to its pre-intervention level. To the contrary, the number of sheets per page remained at the same level as in the weeks immediately after the intervention. By including the 16 printers from the original sample that had duplex as default at the start of the study we can point to another finding. The experiment printers do not reach the same fraction of duplex printing as those that at first had duplex as default, neither immediately nor in the long run, and the difference is statistically significant at the ten percent level $(t(1587)=1.86, p=0.071)$. This highlights the importance of taking self-selection seriously. In fact, if we were restricted to observational data, the treatment effect would appear 50 percent larger due to selection-bias. 
Figure 6: Long run effect

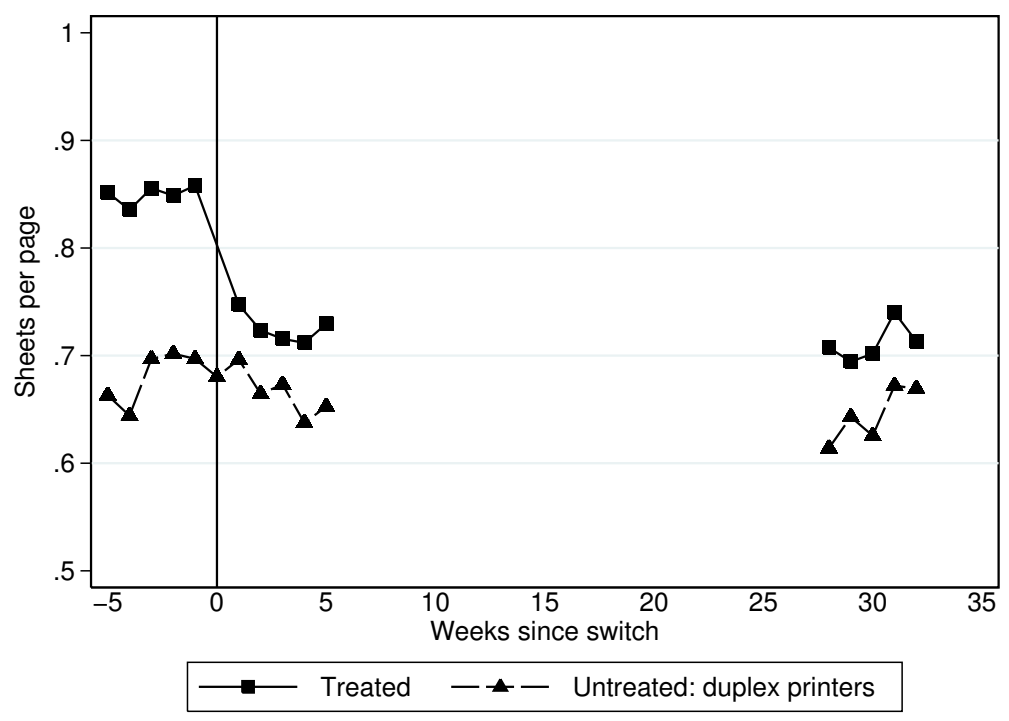

\subsection{Additional Findings}

Four of the printers in the original sample report statistics for each document that is being printed.

Studying these printers separately will show how defaults affect behavior in more detail. In particular, since we are able to study the effect on the number of printed documents, and on document length, we will acquire a better understanding of potential (unintended) demand effects. We can also examine whether there is effect heterogeneity with respect to document length. We suspect that for longer documents users will have a stronger preference for duplex irrespective of the default settings, making it reasonable to think that a potential default effect is larger in magnitude for shorter documents. Two of the four printers belong to one specific department, and the other two printers belong to a second department. We switched the default on one printer from each department resulting in one treatment printer and one control printer in each location. ${ }^{12}$

While prior analysis showed that there is no effect on the number of printed pages, it did not

\footnotetext{
${ }^{12}$ Note that the two printers that we use for treatment are part of the whole 25 printer sample used in the experiment. The reason why we do not use all printers in a staggered manner, as we do for the other 25 printers in the experiment group, is that the departments wanted at least one of their printers to continue to use simplex.
} 
inform us on how document length is affected. In principle, it could be the case that users responded by printing fewer short documents and more long documents (or vice versa). To get a handle on this question, Figure 7 plots the cumulative empirical distribution of document lengths, before and after the default switch, for the two treated printers (left) and the two untreated printers (right). The pattern reveals that a majority of all printed documents are short - about 30 percent of them are only one page long, while less than 20 percent are longer than 10 pages. More importantly, the two curves basically lies on top of each other, implying that document composition is independent of the default option.

Figure 7: Cumulative distribution of document length
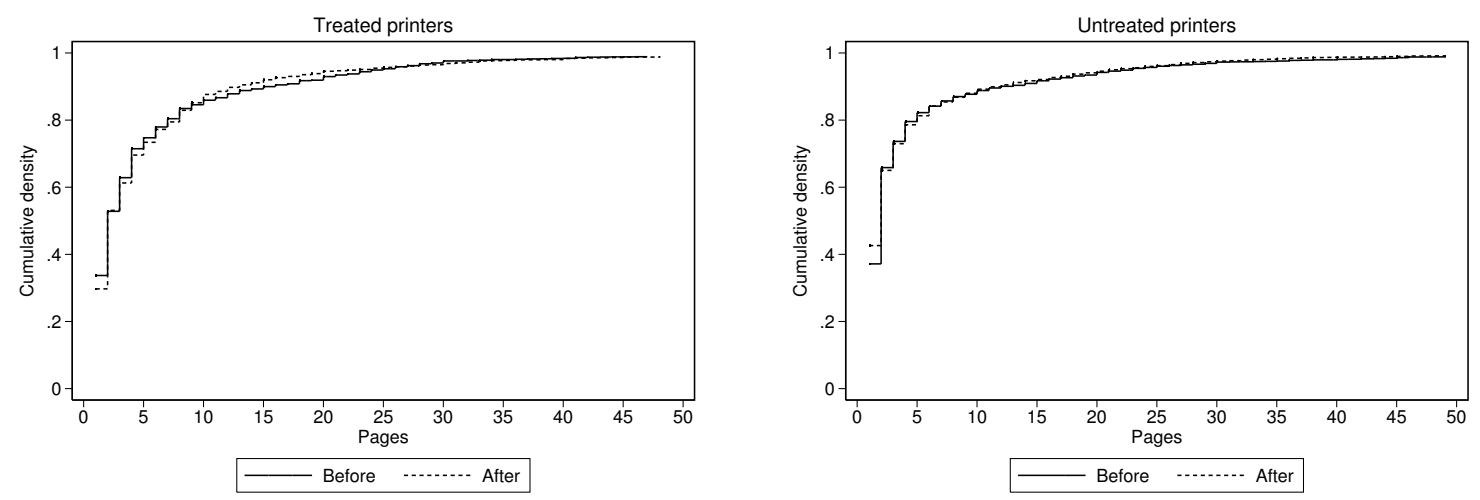

Given that neither the number of printed pages, nor the length of a document, is affected, we draw the conclusion that the number of documents being printed should be unaffected as well. This is confirmed in Figure 8. At first glance, it might appear as if there is a negative effect of switching the default on the number of print jobs. As seen, however, there is a drop for the untreated printers as well. The fact that there is a difference in levels over time is not surprising given that we are restricted to four printers. In addition, the decline is statistically insignificant in both groups. Overall, there is no indication that subjects responded by starting to print more or less document pages, and it seems as if they became neither more or less selective when choosing what to print. In other words, we have rather convincing evidence that when changing the default option there are no distortions with respect to printing volume. 


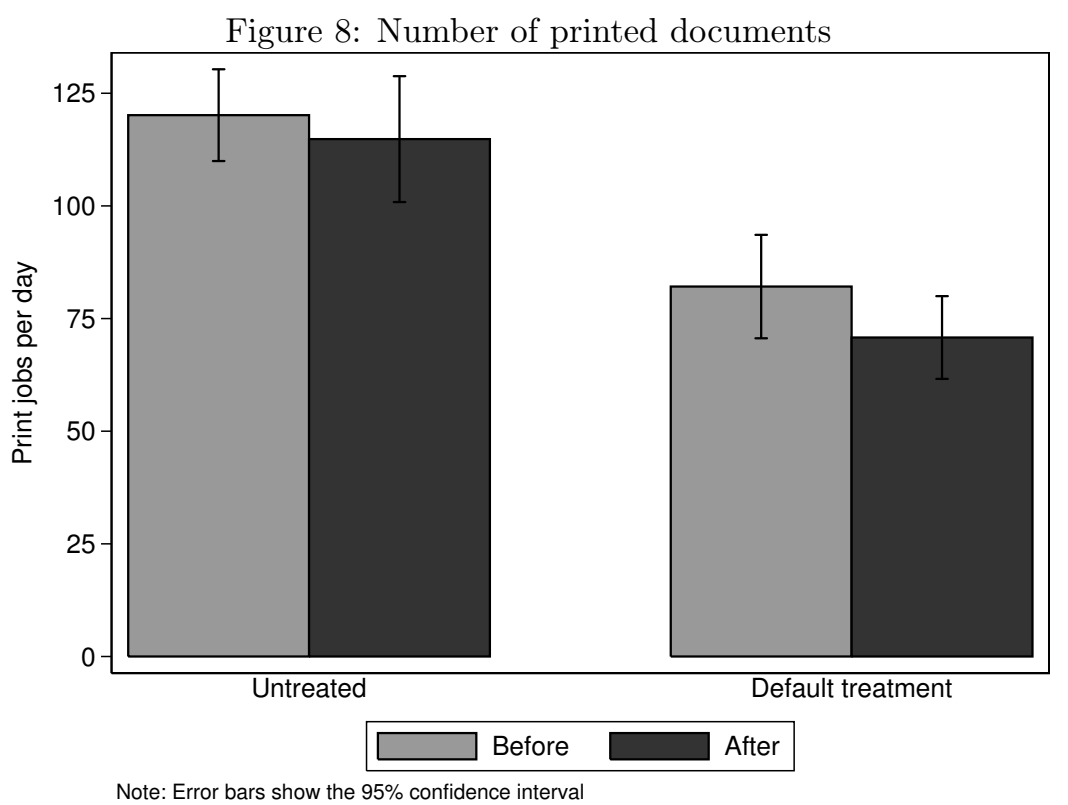

Figure 9 shows the fraction of duplex printing by document lengths, before and after the default treatment. As anticipated, there is considerable effect heterogeneity. For the shortest documents there is almost a doubling of duplex printing whereas there is no effect for documents longer than 40 pages. It is noteworthy that with the new default duplex printing is remarkably stable across document lengths, suggesting that those who opt out of the new default do so for reasons other than document length. Another result neatly captured in the left bar graph is the fact that people actually have a rather strong preference for duplex printing. In particular, even though simplex is the default, people switch to duplex in more than 50 percent of all possible cases (grey bars). 
Figure 9: Fraction duplex by document length
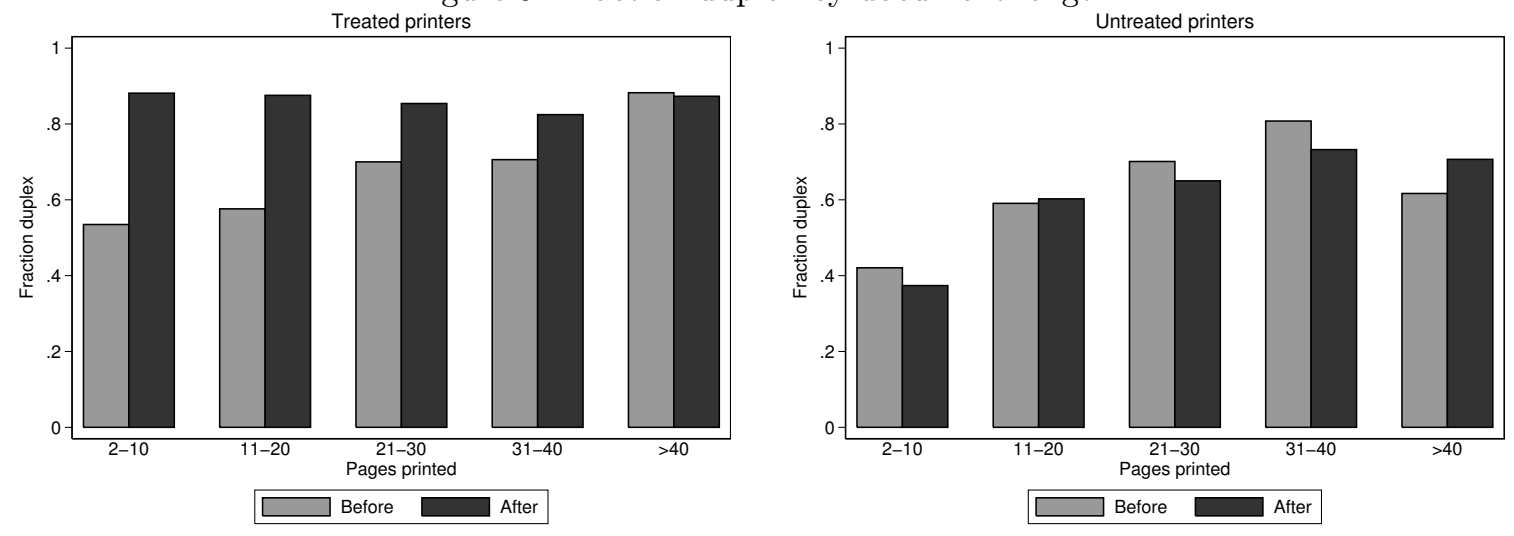

We also use the document-level data to investigate whether the default effect depends on a user's background characteristics. Since this analysis relies on a small sample size - there are 36 employees using the two treatment printers - we are reluctant to draw strong conclusions. That being said, Figure 10 can still provide interesting indications. ${ }^{13}$ We first compare the fraction of duplex documents, before and after the default change, for men and women, respectively. This shows that the default option seems to affect men to a larger extent than women, suggesting that men have a weaker preference in favor of either printing mode. Interestingly, women (on average) seem to prefer duplex printing irrespective of the default, whereas this is not the case for men. We also distinguish "young" and "old" subjects (using age 45 as the cut-off) and conclude that the older an individual is, the more influenced they are. While not shown in the figure, this pattern holds for both men and women, which implies that overall older men are most inclined to stick to the default option in this setting.

\footnotetext{
${ }^{13}$ Since there are no gender or age differences for the untreated printers, we keep things simple by excluding them in the figure.
} 
Figure 10: Fraction duplex by gender (left) and age (right)
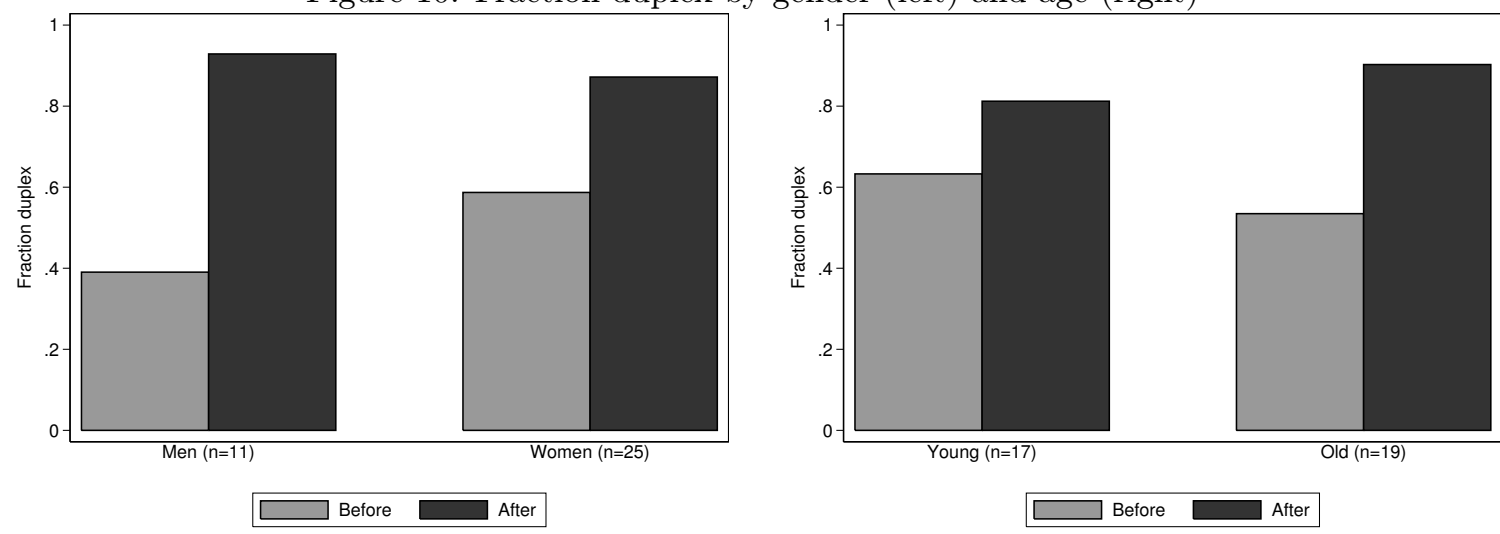

\section{Concluding Remarks}

In a natural field experiment we switch printers' default option (from simplex to duplex printing) at a large Swedish university. The gentle "nudge" reduces paper consumption by as much as $15 \%$. The default effect is immediate and remains more than six months after the intervention. Since printing demand is independent of the default option, we argue that defaults may offer an attractive benefit as a policy tool by avoiding unintended adverse effects. We also show that the more conventional method of encouraging people to save resources has no impact at all. A compelling explanation for the default effect in our setting is that some users have weak preferences between the two alternatives and therefore stick with the default option to avoid a tiny switching cost. Presumably, people do not take the environment into account when making this decision inasmuch as their isolated action will have little (global) impact anyway. Arguably, there are countless other situations where the same logic applies (e.g., turning off the lights when leaving a room, leaving electronic devices on standby, etc.). In such situations, there is a potential in carefully choosing, and creating, "no-action" options. Policy makers should be particularly supportive of this type of intervention since a socially preferred allocation can be reached without spending money or limiting individual choice. One setting that our results can be applied to directly are so-called go paperless-initiatives by for example banks and telephone operators. Another possibility is to use "No receipt" as the default alternative at ATM 
machines, in supermarkets, or any setting where people get receipts but usually have no need for them.

Our results also point to the important role that manufactures have when it comes to choice architecture. Since paper is cheap, the typical department in our experiment annually saves just 60 USD by changing to duplex as default. The weak incentives presented to users illustrates why a general switch is unlikely to occur on its own. Instead, convincing manufactures to set green defaults as machines leave the factory may be the most fruitful strategy to reap benefits on a global scale. Although explicit regulations might be hard to implement, we envision that environmental standards will take on a broader role, by not only helping companies make their internal processes more environmental friendly, but also stimulate their products to be sold with configurations that exploit a resource effective choice architecture. Finally, compared to a suggested ten percent tax on all paper products that would result in a two percent decrease in paper consumption (Axelsson and Åström, 2012), our results illustrate that well-chosen default rules can play an important role and potentially be even more effective than high-powered economic incentives. 


\section{References}

Abadie, A., Gay, S., 2006. The impact of presumed consent legislation on cadaveric organ donation: A cross-country study. Journal of Health Economics 25, 599-620.

Al-Ubaydli, O., List, J. A., 2012. On the generalizability of experimental results in economics. NBER Working Paper 17957.

Allcott, H., 2011. Social norms and energy conservation. Journal of Public Economics 95, 1082-1095.

Allcott, H., Mullainathan, S., 2010. Behavior and energy policy. Science 327 (5970), 1204-1205.

Allcott, H., Rogers, T., 2012. The short-run and long-run effects of behavioral interventions: Experimental evidence from energy conservation. NBER Working Paper 18492.

Anderson, C. D., Claxton, J., 1982. Barriers to consumer choice of energy efficient products. Journal of Consumer Research 9 (2), 163-170.

Anderson, C. J., 2003. The psychology of doing nothing: Forms of decision avoidance result from reason and emotion. Psychological Bulletin 129 (1), 139-167.

Axelsson, S., Åström, K., 2012. Everyone benefits from a paper charge. SSNC.

URL http://www.naturskyddsforeningen.se/nyheter/alla-tjanar-pa-en-pappersavgift

Ayres, I., Raseman, S., Shih, A., 2009. Evidence from two large field experiments that peer comparison feedback can reduce residential energy usage. NBER Working Paper 15386.

Brown, C. L., Krishna, A., 2004. The skeptical shopper: A metacognitive account for the effects of default options on choice. Journal of Consumer Research 31 (3), 529-539.

Carroll, G. D., Choi, J. J., Laibson, D., Madrian, B. C., Metrick, A., 2009. Optimal defaults and active decisions. Quarterly Journal of Economics 124 (4), 1639-1674.

Catlin, J. R., Wang, Y., 2013. Recycling gone bad: When the option to recycle increases resource consumption. Journal of Consumer Psychology 23 (1), 122-127. 
Chen, X., Lupi, F., He, G., Liu, J., 2009. Linking social norms to efficient conservation investment in payments for ecosystem services. Proceedings of the National Academy of Sciences 106 (28), $11812-11817$.

Choi, J. J., Laibson, D., Madrian, B. C., Metrick, A., 2003. Optimal defaults. American Economic Review: Papers and Proceedings 93 (2), 180-185.

Coppen, R., Friele, R. D., Marquet, R. L., Gevers, S. K. M., 2005. Opting-out systems: No guarantee for higher donation rates. Transplant International 18 (11), 1275-1279.

Costa, D. L., Kahn, M. E., 2013. Energy conservation "nudges" and environmentalist ideology: Evidence from a randomized residential electricity field experiment. Journal of the European Economic Association 11 (3), 680-702.

Cullen, L. T., 2007. Going green at the office.

URL http://www.time.com/time/magazine/article/0,9171,1630552,00.html

Dean, M., 2008. Status quo bias in large and small choice sets. Unpublished Working Paper.

DellaVigna, S., 2009. Psychology and economics: Evidence from the field. Journal of Economic Literature 47 (2), 315-372.

Dinner, I., Goldstein, D. G., Johnson, E. J., Liu, K., 2011. Partitioning default effects: Why people choose not to choose. Journal of Experimental Psychology: Applied 17 (4), 332-341.

Fellner, G., Sausgruber, R., Traxler, C., 2013. Testing enforcement strategies in the field: Threat, moral appeal and social information. Journal of the European Economic Association 11 (3), $634-660$.

Fleming, S. M., Thomas, C. L., Dolan, R. J., 2010. Overcoming status quo bias in the human brain. Proceedings of the National Academy of Sciences 107 (13).

Goldstein, N. J., Cialdini, R. B., Griskevicius, V., 2008. A room with a viewpoint: Using social norms to motivate environmental conservation in hotels. Journal of Consumer Research 35, 472 $-482$. 
Haggag, K., Paci, G., forthcoming. Default tips. American Economic Journal: Applied Economics.

Harrison, G. W., List, J. A., 2004. Field experiments. Journal of Economic Literature 42 (4), $1009-1055$.

Johnson, E. J., Goldstein, D., 2003. Do defaults save lives? Science 302, 1338-1339.

Johnson, E. J., Hershey, J., Meszaros, J., Kunreuther, H., 1993. Framing, probability distortions, and insurance decisions. Journal of Risk and Uncertainty 7, 35-51.

Johnson, E. J., Shu, S. B., Dellaert, B. G. C., Fox, C., Goldstein, D. G., Häubl, G., Larrick, R. P., Payne, J. W., Peters, E., Schkade, D., Wansink, B., Weber, E. U., 2012. Beyond nudges: Tools of a choice architecture. Marketing Letters 23, 487-504.

Kahneman, D., 2011. Thinking, Fast and Slow. Farrar, Straus and Giroux.

Kahneman, D., Knetsch, J. L., Thaler, R. H., 1991. Anomalies: The endowment effect, loss aversion, and status quo bias. Journal of Economic Perspectives 5 (1), 193-206.

Kallbekken, S., Sælen, H., Hermansen, E. A. T., 2013. Bridging the energy efficiency gap: A field experiment on lifetime energy costs and household appliances. Journal of Consumer Policy 36 (1), $1-16$.

Löfgren, Å., Martinsson, P., Hennlock, M., Sterner, T., 2012. Are experienced people affected by a pre-set default option - results from a field experiment. Journal of Environmental Economics and Management 63, 66-72.

Madrian, B. C., Shea, D. F., 2001. The power of suggestion: Inertia in 401(k) participation and savings behavior. Quarterly Journal of Economics 116, 1149-1187.

Masatlioglu, Y., Ok, E. A., 2005. Rational choice with status quo bias. Journal of Economic Theory $121(1-29)$.

McKenzie, C. R., Liersch, M. J., Finkelstein, S. R., 2006. Recommendations implicit in policy defaults. Psychological Science 17 (5), 414-420. 
Nolan, J. M., Schultz, P. W., Cialdini, R. B., Goldstein, N. J., Griskevicius, V., 2008. Normative social influence is underdetected. Personality and Social Psychology Bulletin 34 (7), 913-923.

Park, W. C., Jun, S. Y., MacInnis, D. J., 2000. Choosing what I want versus rejecting what I do not want: An application of decision framing to product option choice decisions. Journal of Marketing Research 37 (2), 187-202.

Pichert, D., Katsikopoulos, K. V., 2008. Green defaults: Information presentation and proenvironmental behaviour. Journal of Environmental Psychology 28, 63-73.

Samuelson, W., Zeckhauser, R., 1988. Status quo bias in decision making. Journal of Risk and Uncertainty 1 (1), 7-59.

Schultz, P. W., Nolan, J. M., Cialdini, R. B., Goldstein, N. J., Griskevicius, V., 2007. The constructive, destructive, and reconstructive power of social norms. Psychological Science 18 (5), $429-434$.

Shafir, E. (Ed.), 2012. The Behavioral Foundations of Public Policy. Princeton University Press.

Sunstein, C. R., Reisch, L. A., 2013. Automatically green: Behavioral economics and environmental protection. Preliminary draft 4/5/2013.

Thaler, R. H., Sunstein, C. R., 2008. Nudge: Improving Decisions About Health, Wealth, and Happiness. Yale University Press. 


\section{A Print Screens}

Figure 11: Print screen (simplex default)

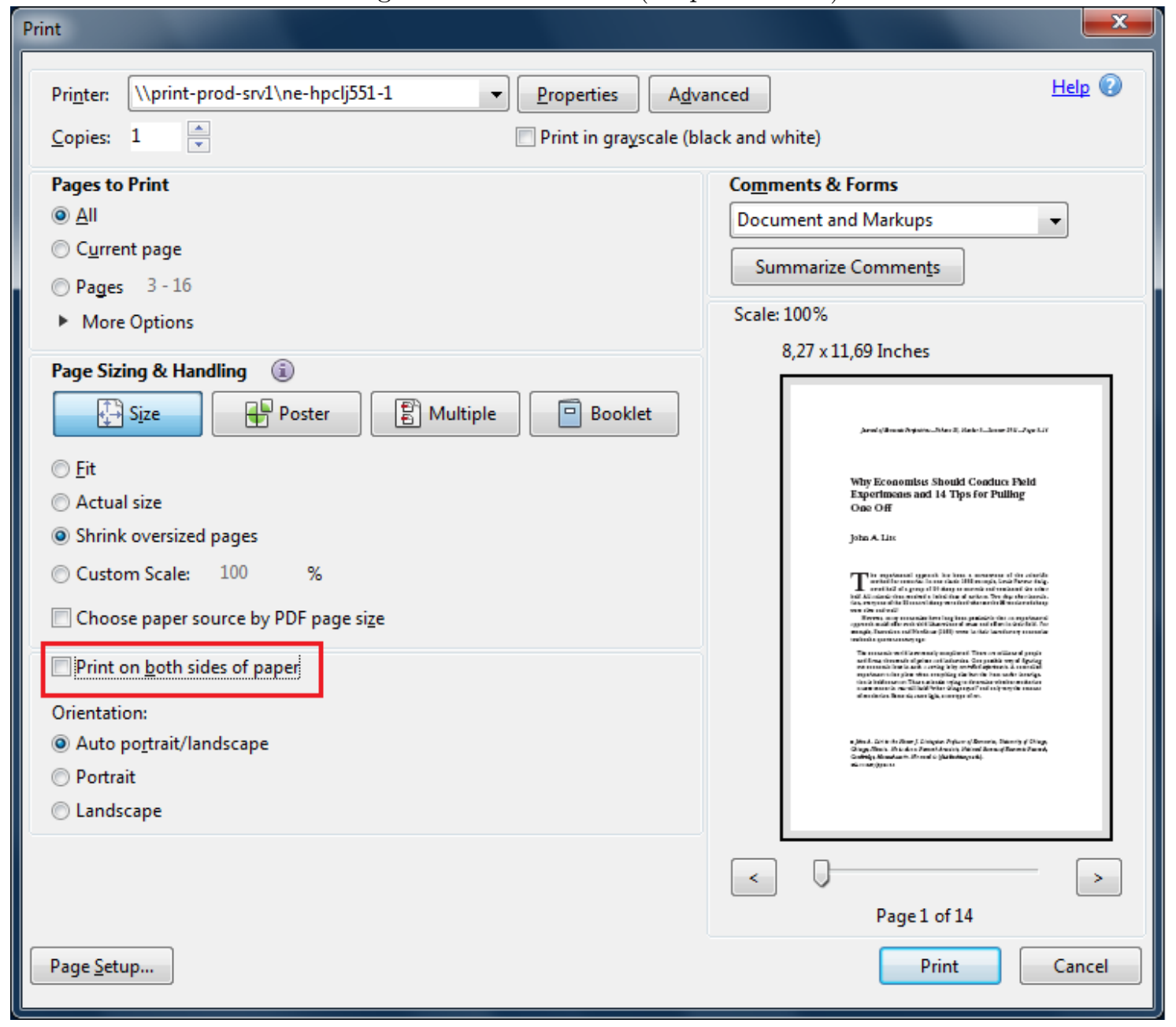


Figure 12: Print screen (duplex default)

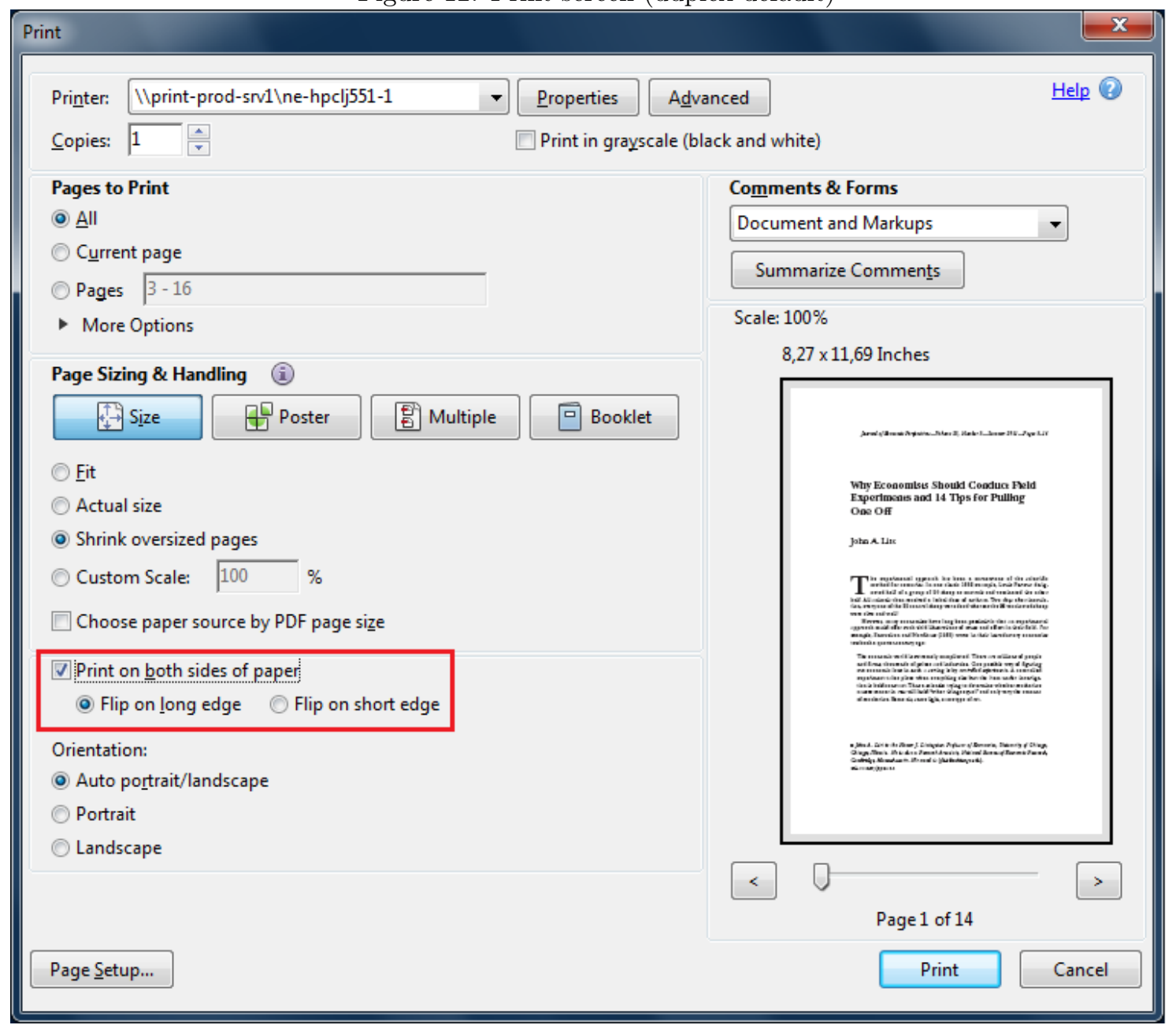




\section{B Letters}

\section{B.1 Encouragement Letter}

Dear Colleague,

At $\mathrm{X}$ we strive to reduce our impact on the environment, and as an employee you can be part of this process. An easy way to save resources is to keep paper consumption low. You can contribute by choosing to print on both sides of a sheet. Duplex printing is available on most of the printers at $\mathrm{X}$, and you can also make this printing mode the default option on your computer. Thank you for your cooperation!

Best regards

X X, Environmental coordinator, Faculty

X X, Environmental coordinator, The Environmental council

\section{B.2 Default Switch Notice}

Dear Colleague,

In order to save the environment and resources, we have decided to change the default setting from simplex to duplex printing on printer $\mathrm{X}$. The change enters into force tomorrow, $\mathrm{x} / \mathrm{x}-2012$. The possibility to print simplex remains, and if you absolutely want one-sided print jobs as a preselection, you can change your personal default to simplex. This is done under "Printer Settings" on your particular computer. If you have any problems in the transition or if you want help with your own printer settings, you can contact the IT media helpdesk by phone: XX-XXXXXX.

Best regards

X X, Head of Department 